\title{
Türk Bankacılık Sektöründe Mevduat Bankalarının Finansal Performanslarının DuPont Sistemine Göre İncelenmesi: 2015-2019 Dönemi ${ }^{1}$
}

\author{
DOI: 10.26466/opus.930091 \\ *
}

Erdal Arslan* - Ali Bora**

* Doç. Dr., Selçuk Üniversitesi, İ̈BF, İktisat Bölümü, Konya/Türkiye

E-Posta: erdalarslan@selcuk.edu.tr

ORCID: $\underline{0000-0003-4892-2963}$

** Dr. Öğr. Üyesi, Selçuk Üniversitesi, Sosyal Bilimler MYO, Konya /Türkiye

E-Posta: ali.bora@selcuk.edu.tr

ORCID: $\underline{0000-0002-1766-0123}$

Öz

Türk Bankacllk Sektöründe mevduat bankaları sermaye sahipliğine göre kamu sermayeli mevduat bankaları, özel sermayeli mevduat bankaları ve yabancı sermayeli mevduat bankaları olarak gruplandirlmaktadır. 2015 yılından itibaren Türk Bankacilık sisteminde 3 kamu sermayeli mevduat bankası, 9 özel sermayeli mevduat bankası ve 21 yabancı sermayeli mevduat bankası faaliyetine devam etmektedir. DuPont sistemi ilk başlarda şirketlerin finansal performanslarmı, finansal oranlardan özkaynak karlılığı ile ölçmek için kullanılan, daha sonra bankacıllk sektörüne uyarlanarak bu sektörde de kullanılmaya başlanan bir finansal analiz tekniğidir. DuPont sisteminde özkaynak karlılığının kaynağı detaylı olarak analiz edilmektedir. Bu çalışmada Türk Bankacılık Sektöründe faaliyet gösteren mevduat bankaları sermaye sahipliğine göre gruplandırlarak, 2015-2019 yılları arası finansal performansları DuPont sistemine göre karşılaştırmalı olarak incelenmektedir. Kamu sermayeli mevduat bankaları 2015-2018 yilları arasında sektör ortalamasını üzerinde özkaynak karlılığı elde ederken 2019 yılında sektör ortalamasının altında özkaynak karlılığı elde etmiş, özel sermayeli mevduat bankaları ağırlıklı olarak sektör ortalamasının altında kalmış, yabancl sermayeli mevduat bankalarn ise özellikle 2018 ve 2019 yıllarında sektör ortalamasinın üzerinde özkaynak karlılığına sahip olmuşlardır. Bu çalışmada özellikle sektör ortalamasının altında özkaynak karlılı̆̆ı elde eden banka gruplarının başarısızlıklarının kaynakları DuPont sistemi ile incelenmektedir. Çalışmada Türkiye Bankalar Birliğinin yayınlamış olduğu istatistikler ve raporlardan elde edilen veriler kullanılmıştır.

\section{Anahtar Kelimeler: DuPont Sistemi, Finansal Oran Analizi, Türk Bankacılık Sistemi, Bankaların Performansları, Özkaynak Karlılığı.}

\footnotetext{
${ }^{1}$ Bu çalışma 26-27 Ey/ül 2020 tarihlerinde Plovdiv/Bulgaristan'da düzenlenen "XIV. International Balkan and Near Eastern Congress Series on Economics, Business and Management" kongresinde sunulan bildiriden makale haline getirilmiştir.
} 


\title{
Analysis of the Financial Performance of Deposit Banks in the Turkish Banking Sector According to DuPont System: 2015-2019 Period
}

\begin{abstract}
In the Turkish Banking System, deposit banks are grouped according to their capital structures as state-owned, private-owned and foreign-owned banks. Since 2015, 3 state-owned deposit banks, 9 private-owned deposit banks and 21 foreign-owned deposit banks have been operating in the Turkish Bakning System. The DuPont system is a financial analysis technique primarily used to measure the financial performance of the companies by their return on equity from financial ratios, then adapted to banking sector and used in this sector. In the DuPont system, the sources of return on equity is analyzed in detail. In this study, deposit banks operating in the Turkish banking sector are grouped according to capital ownership and their financial performance between 2015-2019 is examined comparatively according to the DuPont system. State-owned deposit banks between the years 2015-2018, while getting a return on equity above the industry average achieved a return on equity lower than the sector average in 2019, private-owned deposit banks under the industry average, foreign-owned deposit banks particularly in 2018 and 2019 have return on equity above the industry average. In this study, the sources of failures of bank groups that achieve return on equity below the sector average are examined with DuPont system. In the study, data obtained from statistics and reports published by The Banks Association of Turkey were used.
\end{abstract}

Keywords: DuPont System, Financial Ratio Analysis, Turkish Banking System, Performance of Banks, Return on Equity. 


\section{Giriş}

Bankaların faaliyetleri sonucunda ortaya çıan finansal performansları değişik yöntemlerle ölçülmektedir. Bu ölçme yöntemlerinden biri de finansal oran analizidir. Bu yöntem kolay anlaşılabilir olması nedeni ile tercih edilmektedir. DuPont sistemi çoklu oran analizi yöntemi olarak da ifade edilmektedir. Bu analizde banka faaliyetleri sonucu özkaynak karlılığına göre değerlendirilmektedir. Özkaynak karlılığı banka sahip ve ortakların bankaya sermaye olarak koydukları her bir TL karşılığı elde ettiği karı göstermektedir. Bu çerçevede özkaynak karlılığı banka sahip ve ortakları ile potansiyel yatırımcılar için önemli bir gösterge olmaktadır. Diğer bankalarla karşılaştırılarak bir bankanın özkaynak karlılığına göre başarılı ya da başarısı olduğu ortaya konabilmektedir. Özkaynak karlılığında problem olan bankanın bu başarısızlığının nedeni DuPont sistemine göre özkaynak karlılığı bileşenleri incelenerek ortaya konabilmektedir. Türk Bankacılık Sektöründe sahiplik yapılarına göre mevduat bankaları kamu sermayeli, özel sermayeli ve yabancı sermayeli mevduat bankaları olarak gruplandırılmaktadır.

Türk Bankacılık Sektöründe sahiplik yapılarına göre banka gruplarının sayısı incelendiğinde yıllar itibariyle artış gösterse de 1954 yılında 14 olan kamu sermayeli mevduat bankası sayısı 1964 yılında 12'ye, 1986 yılında 8'e, 1992'de 6'ya, 1995'te 5'e, 1998'de 4'e gerilemiş, 2001 yılında 3'e düştükten sonra bu yıldan itibaren 3 olarak varlığını devam ettirmiştir. 2006 yılına kadar özel sermayeli mevduat bankalarının sayısı yabancı sermayeli mevduat bankalarının sayısından yüksek olurken, 2006 yılında bu durum değişmiş ve yabancı sermayeli mevduat bankaları sayı olarak özel sermayeli mevduat bankalarını geçmiştir. 2015 yılından itibaren Türk Bankacılık Sektöründe 3 kamu sermayeli mevduat bankası, 9 özel sermayeli mevduat bankası ve 21 yabancı sermayeli mevduat bankası faaliyetine devam etmektedir.

Çalışmanın giriş bölümünden sonra gelen literatür incelemesinde DuPont sistemi kullanılarak yapılan banka finansal performans incelemeleri ile ilgili çalışmalar ve ulaşılan sonuçlar değerlendirilmiş, üçüncü bölümde Türkiye Bankalar Birliği (TBB) istatistik ve raporları kullanılarak 2015-2019 dönemi Türk Bankacılık Sektörünün yapısı ile ilgili bilgiler verilmiş, dördüncü bölümde DuPont sistemi ve bileşenleri hakkında 
bilgi verilmiş ve beşinci bölümde Türk Bankacılık Sektöründe sahiplik yapılarına göre bankalar DuPont finansal analiz yöntemine göre incelenmiştir.

\section{Literatür İncelemesi}

Ajmera (2012) tarafından yapılan çalışmada DuPont modeli ile 2006-2011 yılları arası bankacılık sektörünün finansal sağlığı analiz edilmiş, PBIDT/Satışlar oranı en yüksek banka SBI, Satışlar/Net varlıklar oranı en yüksek Corporation Bankası, PBDIT/Net varlık oranı en yüksek SBI, Dena Bank ve Corporation Bankası, PAT/PBDIT oranı en yüksek Dena Bank, Net varlık/Net değer oranı en yüksek Baroda Bank ve Özkaynak karlılık oranı (ROE) en yüksek SBI olarak belirlenmiştir (Ajmera, 2012, s.58).

Balaj (2015) tarafından yapılan çalışmada Kosova'da yerli ve yabancı bankaların 2001-2007 dönemine ait finansal performansları DuPont finansal analiz modeli kullanılarak karşılaştırmalı olarak incelenmiş; yabancı bankaların daha etkin ve karlı olduğu, daha yüksek aktif karlılığı ve özkaynak karlılıklarına sahip olduğu belirlenmiştir. Yabancı bankaların yüksek özkaynak karlılık oranları yüksek faiz marjından kaynaklandığı belirlenmiş, bu durum, yabancı bankaların maliyet yönetiminin daha iyi olduğu ve yüksek kaldıraç oranı kullandıklarının göstergesi olarak değerlendirilmiştir. Yabancı bankalarla karşılaştırıldığında yerli bankaların daha yüksek aktif verimliliğine rağmen düşük karlılığının nedeni zayıf kalitede kredi portföyüne bağlı olarak yüksek kredi karşılıkları maliyetleri olarak belirlenmiştir. Buna göre, yerli bankaların çoğunlukla düşük kredibiliteye sahip müşterilere sahip olduğu sonucuna ulaşılmıştır (Balaj, 2015, s.71).

Haider (2016) tarafından yapılan çalışmada Hindistan bankacılık sektörünün en büyük kamu ve özel sermayeli bankalarından Baroda Bank ve HDFC Bank'ın finansal karlılığı Dupont yöntemiyle analiz edilmiş, HDFC Bank'ın Baroda Bank'a göre finansal kaynakları daha etkin yönettiği sonucuna ulaşılmıştır (Haider, 2016, s.9).

Rooplata (2016) tarafından yapılan çalışmada Hindistan'da 19 ulusal banka performansı DuPont analiz yöntemiyle incelenmiş, sonuçta Baro- 
da Bank ile India Bank karşılaştırılmış, Baroda Bank son beş yılda en yüksek karı elde etmesine rağmen India Bank daha yüksek özkaynak karlılığ1 elde etmiştir. Bu durumda daha yüksek kar elde eden bankanın daha yüksek özkaynak karlılığı elde edeceği anlamına gelmediği sonucuna ulaşılmıştır (Rooplata, 2016, s.211).

Rahman ve Mia (2018) tarafından yapılan çalışmada 15 Bangladeş ticaret bankasının DuPont yöntemiyle 2010-2016 dönemine ait finansal performansları incelenmiş, çalışma sonucunda Dhaka Bank en yüksek, $\mathrm{AB} B a n k^{\prime}$ in ise en düşük özkaynak karlılığına sahip olduğu belirlenmiştir (Rahman ve Mia, 2018, s.165).

AlAli (2019) tarafından yapılan çalışmada Kuveyt bankalarının 20122017 dönemi finansal performansları DuPont sistemine göre analiz edilmiş, National Bank of Kuwait aktif karlılığa göre en iyi banka, Ahli United bankası ikinci en iyi banka olmuş, özkaynak karlılığına göre ise Ahli United bankası en iyi performansa sahip banka, National Bank of Kuwait ise ikinci en iyi banka olmuştur. Diğer taraftan en kötü performansa sahip bankanın ise Warba bankası olduğu, AlAhli bankasının da onu takip ettiği belirlenmiştir (AlAli, 2019, s.1-6).

Ülkelerle ilgili yapılan çalışmaların yanında ülkemizde Bankacılık Sektöründe faaliyet gösteren bankaların finansal performansları ile ilgili çalışmalar da mevcuttur. Bunlardan Önal ve Sevimeser (2006) Türk bankacılık sektöründeki bankaların sahiplik yapılarına göre etkinliklerini incelemiş, çalışma sonucunda en etken banka grubunun yabancı bankalar olduğu sonucuna ulaşılmıştır (Önal ve Sevimeser, 2006, s.295).

Aktaş ve Kargın (2007), Türk bankacılık Sisteminde faaliyet gösteren yabancı bankalar ile kamu ve yerli özel bankaları bazı finansal oranlar açısından, 2003 - 2006 dönemi için karşılaştırmış, çalışmanın sonucunda yabancı bankaların daha yüksek sermaye yeterlilik ve likidite oranlarına sahip olduğunu belirlemiştir (Aktaş ve Kargın, 2007, s.44).

Akbulut ve Albayrak (2009) çalışmalarında, Türkiye'de mülkiyet yapısı açısından bankaların performansı ve bu mülkiyet yapılarının hangi faktörlere göre ayrıştığını incelemiş, Çalışmada temel bileşenler analizi ile mevduat bankaları için yıllara göre performans endeksleri elde edilmiş, elde edilen endekslere göre genelde yabancı bankaların özel ve kamu bankalarından daha iyi bir performansa sahip olduğu sonucuna ulaşılmıştır (Akbulut ve Albayrak, 2009, s.27). Ata (2009) çalışmasında, ül- 
kemizde bankacılık sektöründe yer alan yerli ve yabancı bankaların finansal performanslarını ve sektöre yabancı sermaye girişinin bankaların performansı üzerindeki etkisini incelemiş, performans göstergeleri açısindan yerli bankaların yabancı bankalara oranla daha etkin olduğu, ancak özellikle faiz dişı giderin toplam aktife oranı, aktif karlılığı ve faaliyet karının toplam aktife oranı açısından yabancı bankaların etkinliğinin arttığı sonucuna ulaşmıştır (Ata, 2009, s.109). Yücel (2009), ülkemizde faaliyet gösteren $3 \mathrm{kamu}, 10$ özel sermayeli mevduat bankası ve 11 Türkiye'de kurulmuş yabancı bankadan oluşan 24 bankanın, 2002-2007 yılları arasındaki performanslarını incelemiş, çalışmanın sonucunda 2002 yılında kamu bankalarının; sermaye, likidite, kredi ve karlılık oranları bakımından yabancı bankalar ve özel sermayeli bankaların önüne geçtiklerini, 2005 yılında ise yabancı ve özel sermayeli bankaların lehine dönmeye başladığını belirlemiştir (Yücel, 2009, s.118).

Demirel, Atakişi ve Abacıoğlu (2013), özel, kamu ve yabancı mevduat bankalarının faaliyet oranlarını ve karlılık göstergelerini, 2002 Mart 2012 Haziran arasında üçer aylık veriler kullanarak incelemiş, çalışma sonucunda, "personel giderleri / toplam aktif" ve "operasyonel giderler / toplam aktif" oranlarında kamu bankalarının daha verimli çalıştığını, özel karşılıklar sonrası net faiz geliri / toplam aktifler oranında kamu sermayeli mevduat bankalarının, net faiz geliri / toplam aktifler oranında ise yabancı sermayeli bankaların daha yüksek karlılık göstergelerine sahip olduğu belirlemiştir (Demirel, Atakişi ve Abacıŏlu, 2013, s.101, 110). Kandemir ve Arıcı (2013), ülkemizde faaliyet gösteren mevduat bankalarını sahiplik yapılarına göre gruplandırarak 2001 - 2010 dönemine ait performanslarını karşılaştırmalı olarak incelemiş, çalışma sonucunda, 2001 krizi sonrasında mevduat bankalarının yüksek sermaye yeterlilik ve likidite oranlarına sahip olduğu, yabancı sermayeli mevduat bankalarının aktif kalitesi ve yönetim kalitesi açısından en iyi performans gösteren banka grubu olduğu sonucuna ulaşmıştır (Kandemir ve Aric1, 2013, s.61, 83).

Gümüş ve Nalbantoğlu (2015) tarafından yapılan çalışmada, kamu, yerli özel, yabancı sermayeli ve katılım bankalarından oluşan Türk Bankacılık Sektörünün 2002 - 2013 dönemi performansı, CAMELS analiz yöntemiyle karşılaştırmalı olarak incelenmiş, çalışma sonucunda, yerli özel sermayeli bankaların yönetim kalitesi ve karlılıkta başarılı perfor- 
mans gösterdiği ve güçlü sermaye yapıları ile en yüksek nota sahip banka grubu olduğu belirlenmiştir (Gümüş ve Nalbantoğlu, 2015, s.83).

Arslan (2017) tarafından yapılan çalışmada Türk Bankacılık Sisteminde aktif büyüklüğüne göre ilk yedi bankanın 2003-2015 dönemi faaliyetleri oran analizi yöntemi ile karşılaştırmalı olarak incelenmiş, çalışma sonucunda sektör paylarına göre bankalar sıralandığında; incelenen oranların tamamında aynı kamu bankası ilk sırayı alırken, karlılık oranlarında; sektör paylarında ilk sırayı alan kamu bankası incelenen dört orandan ikisinde ilk sırayı almakta, diğer iki orandan birinde özel sermayeli banka diğerinde ise yabancı sermayeli banka ilk sırayı aldığı belirlenmiştir (Arslan, 2017, s.226).

Gümüş ve Çıbık (2018) tarafından yapılan çalışmada DuPont yöntemi kullanılarak borsada işlem gören gayrimenkul yatırım ortaklığ şirketleri içindeki 25 şirketin özsermaye verimlilik analizleri yapılmış, bu analizler sonucunda en iyi işletme Ak Merkez GYO işletmesi olduğu, şirketin özsermaye verimliliğinin yüksek olmasının sebebi net kar marjının yüksek olması ve aktif devir hızı oranının da diğer işletmelere göre yüksek olması sonucuna ulaşılmıştır (Gümüş ve Çıbık, 2018, s.2178, 2192).

\section{Türkiye'de 2015-2019 Dönemi Bankacılık Sisteminin Yapısı}

Türk Bankacılık Sisteminde mevduat bankaları sermaye yapılarına göre kamu sermayeli mevduat bankaları, özel sermayeli mevduat bankaları ve yabancı sermayeli mevduat bankaları olarak gruplandırılmaktadır. Yıllar itibariyle artışlar gösterse de 1954 yılında 14 olan kamu sermayeli mevduat bankası sayısı 1964 yılında 12'ye, 1986 yılında 8'e, 1992'de 6'ya, 1995'te 5'e, 1998'de 4'e gerilemiş, 2001 yılında 3'e düştükten sonra bu yıldan itibaren 3 olarak varlığını devam ettirmiştir. 2006 yılına kadar özel sermayeli mevduat bankalarının sayısı yabancı sermayeli mevduat bankalarının sayısından yüksek olurken, 2006 yılında bu durum değişmiş ve yabancı sermayeli mevduat bankaları sayı olarak özel sermayeli mevduat bankalarını geçmiştir. (Türkiye Bankalar Birliği, 2020). 
Tablo 1. Türk Bankacılık Sisteminde Sahiplik Yapılarına Göre Banka Sayıları, 20152019

\begin{tabular}{llllll}
\hline Mevduat Bankaları & $\mathbf{2 0 1 5}$ & $\mathbf{2 0 1 6}$ & $\mathbf{2 0 1 7}$ & $\mathbf{2 0 1 8}$ & $\mathbf{2 0 1 9}$ \\
\hline Kamu Sermayeli & 3 & 3 & 3 & 3 & 3 \\
Özel Sermayeli & 9 & 9 & 9 & 9 & 9 \\
Yabancı Sermayeli & 21 & 21 & 21 & 21 & 21 \\
Toplam & $\mathbf{3 3}$ & $\mathbf{3 3}$ & $\mathbf{3 3}$ & $\mathbf{3 3}$ & $\mathbf{3 3}$ \\
\hline
\end{tabular}

Kaynak: Türkiye Bankalar Birliği, 2020.

Tablo 1'e göre 2015-2019 dönemi boyunca Türk Bankacılık sisteminde 3 kamu sermayeli mevduat bankası, 9 özel sermayeli mevduat bankası ve 21 yabancı sermayeli mevduat bankası faaliyet göstermiştir.

Tablo 2. Bankaların Sektör Payları (\%), 2019

\begin{tabular}{llll}
\hline Mevduat Bankaları & Toplam Aktifler & Krediler & Mevduat \\
\hline Kamu Sermayeli & 36,3 & 38,5 & 40,3 \\
Özel Sermayeli & 33,2 & 30,6 & 35,1 \\
Yabancı Sermayeli & 23,2 & 22,0 & 24,7 \\
\hline
\end{tabular}

Kaynak: Türkiye Bankalar Birliği, 2020.

Tablo 2'ye göre bankaların sektör payları toplam aktifler, krediler ve mevduata göre 2019 yılı için incelendiğinde; kamu sermayeli mevduat bankalarının diğer iki banka grubundan daha yüksek paya sahip olduğu görülmektedir. Özel sermayeli bankalar kamu sermayeli bankaların ardından ikinci sırada gelmektedir.

\section{Dupont Finansal Analiz Yöntemi}

Birleşik oranlar analizi olarak da ifade edilen DuPont sistemi ilk kez 1919 yılında bir kimya firması olan Du-pont firması tarafından kullanıldığı için bu isimle isimlendirilmektedir (Gümüş ve Çıbık, 2019, s.2182). Bu analiz yöntemi öncelikle şirketler tarafından kullanılmış, daha sonra model geliştirilerek bankacılık sektöründe finansal performansın ölçümü için kullanılmaya başlanmıştır (Balaj, 2015, s.72). Bu sistemde özkaynak karlılığının kaynağı detaylı olarak analiz edilmektedir. 


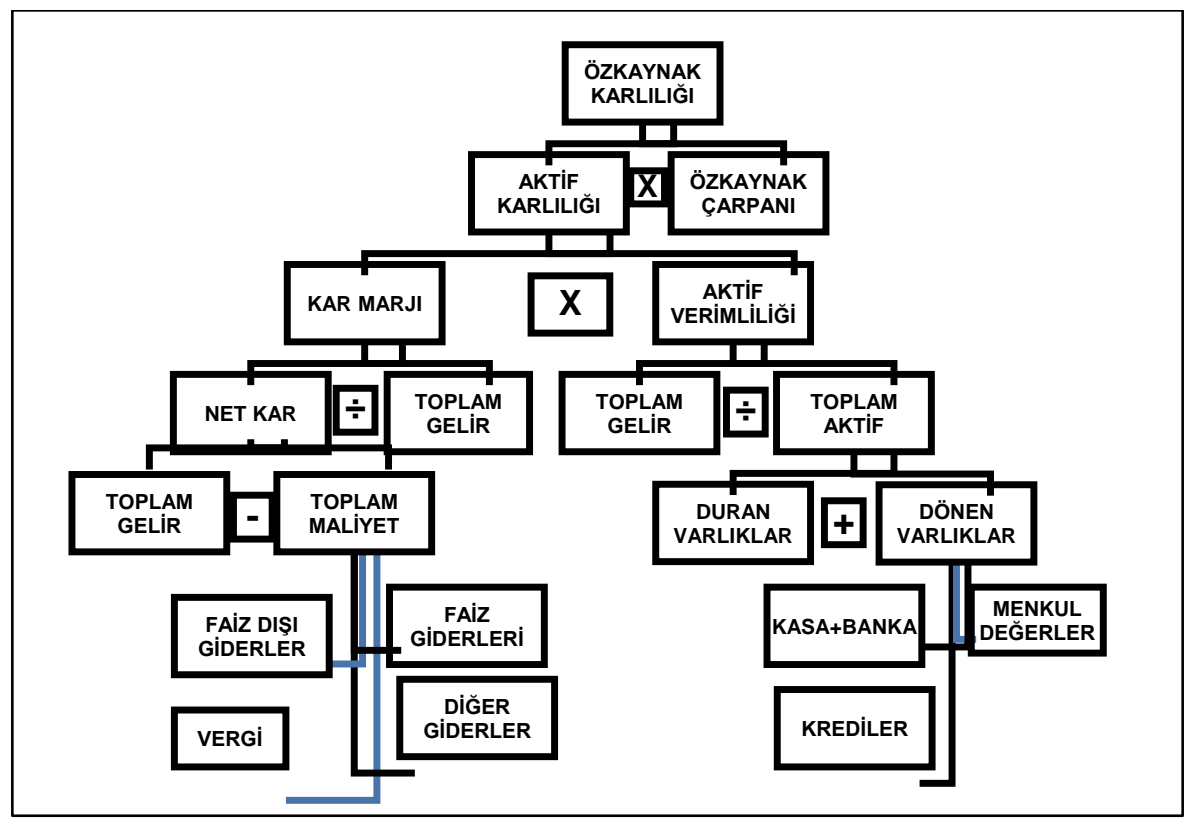

Şema 1. Bankacılık Sektörü Açısından DuPont Şeması

Kaynak: Berk, 1999, s.53; Tandon vd., 2016, s.66.

DuPont sistemi, işletmenin dönemsel faaliyetinin sonucunu nihai olarak özkaynak karlılığı ile ölçen çoklu finansal oran analizi yöntemidir. Şema 1'de gösterilen özkaynak karlılığını oluşturan bileşenler aşağıdaki şekilde formüle edilmektedir (Rose ve Fraser, 1988, s.201).

Özkaynak Karlılığ $1=\quad \frac{\text { Net Kar }}{\text { Toplam Özkaynak }}$

Özkaynak Karlılığı = Aktif Karlılığı X Özkaynak Çarpanı

\begin{tabular}{lllll} 
Özkaynak Karlılığ $=$ & \multicolumn{2}{l}{ Net Kar } & & \multicolumn{2}{l}{ Toplam Aktifler } \\
\cline { 2 - 3 } Aktif Karlılığ $1=$ & Toplam Aktifler & & Toplam Özkaynak \\
Özkaynak Karlılığ $=$ & Kar Marjı & $X$ & Aktif Verimliliği & $(4)$ \\
Kar Marjı & $X$ & Aktif Verimliliği X Özkaynak Çarpanı & (5)
\end{tabular}

Özkaynak karlılığı dönem sonu elde edilen net karın toplam özkaynaklara bölünmesi (1) ile bulunmaktadır. Özkaynak karlılığı aktif karlılığ1 ile özkaynak çarpanının çarpılması (2) sonucu da hesaplanabilmektedir. Aktif karlılığı kar marjı ile aktif verimliliği çarpılarak elde (4) edildiği dikkate alındığında özkaynak karlılığı; kar marjı, aktif verimliliği ve özkaynak çarpanının çarpılması (5) ile hesaplanabilmektedir. Eğer bankanın özkaynak karlılığında bir problem varsa bu problemin kaynağının 
bulunması açısından bu formül yol gösterici olmaktadır. Buna göre bir bankanın özkaynak karlılığı sektör ortalamasının altında kalmışsa bunun nedeninin kar marjından $\mathrm{ml}$, aktif verimliliğinden mi yoksa özkaynak çarpanından $\mathrm{m} ı$ kaynaklandığı kolayca belirlenebilmektedir.

\section{Türk Bankacılık Sektöründe Sahiplik Yapılarına Göre Bankaların Dupont Finansal Analiz Yöntemine Göre İncelenmesi}

Bu bölümde banka gruplarının 2015-2019 dönemine ait finansal performansları DuPont sistemine göre incelenecektir. Bu incelemede önce özkaynak karlığ alınacaktır.

\section{Özkaynak Karlılığı ve Bileşenlerinin Analizi}

Özkaynak karlılığı net dönem karının özkaynaklara bölünmesiyle hesaplanmakta ve banka sahip ve ortaklarının bankaya sermaye olarak koydukları her bir TL karşılığı elde ettiği karı göstermektedir. Özkaynak karlılığ1 ayrıca aktif karlılığı ile özkaynak çarpanının çarpılmasıyla hesaplanabilmektedir. Aktif karlılığı net dönem karının toplam aktiflere bölünmesiyle elde edilmektedir. Bankanın yapmış olduğu gelir getirici yatırımlar (plasmanlar) ile üstlendiği risk derecesini gösteren özkaynak çarpanı toplam aktiflerin özkaynaklara bölünmesi ile elde edilir. Finansal analiz sonucunda özkaynak karlılı̆̆ı düşük olan bankanın bu olumsuzluğunun kaynağı aktif karlılığının veya özkaynak çarpanının düşük olmasında aranır. Banka ya aktiflerini karlı plasmanlarda kullanmamıştır veya özkaynaklara göre daha az aktif bulundurmaktadır. Tablo 3'te banka gruplarının 2015-2019 dönemi özkaynak karlılı̆̆1 ve bileşenleri incelenmekte, ardından tablo değerlendirilmektedir.

Tablo 3. Özkaynak Karlılı̆̆ı ve Bileşenleri

\begin{tabular}{lllllll}
\hline \multicolumn{2}{l}{ Özkaynak Karlılığı (Net Dönem Karı / Özkaynak) (\%) } & & & & \\
\hline Mevduat Bankaları & $\mathbf{2 0 1 5}$ & $\mathbf{2 0 1 6}$ & $\mathbf{2 0 1 7}$ & $\mathbf{2 0 1 8}$ & $\mathbf{2 0 1 9}$ & Ortalama \\
Kamu Sermayeli & 14,7 & 16,1 & 17,5 & 13,5 & 8,7 & 14,1 \\
Özel Sermayeli & 9.0 & 13,5 & 13,6 & 13,2 & 10,0 & 11,9 \\
Yabancı Sermayeli & 11,0 & 12,3 & 13,7 & 14,3 & 12,5 & 12,8 \\
Sektör Ortalaması & $\mathbf{1 0 , 8}$ & $\mathbf{1 3 , 5}$ & $\mathbf{1 4 , 3}$ & $\mathbf{1 3 , 4}$ & $\mathbf{1 0 , 6}$ & $\mathbf{1 2 , 5}$ \\
\hline
\end{tabular}

Aktif Karlıı̆̆ı (Net Dönem Karı / Aktifler) (\%) 


\begin{tabular}{lllllll} 
Mevduat Bankaları & $\mathbf{2 0 1 5}$ & $\mathbf{2 0 1 6}$ & $\mathbf{2 0 1 7}$ & $\mathbf{2 0 1 8}$ & $\mathbf{2 0 1 9}$ & Ortalama \\
Kamu Sermayeli & 1,5 & 1,6 & 1,7 & 1,2 & 0,7 & 1,3 \\
Özel Sermayeli & 1,0 & 1,5 & 1,5 & 1,5 & 1,2 & 1,3 \\
Yabancı Sermayeli & 1,2 & 1,4 & 1,5 & 1,6 & 1,5 & 1,4 \\
Sektör Ortalaması & $\mathbf{1 , 2}$ & $\mathbf{1 , 5}$ & $\mathbf{1 , 6}$ & $\mathbf{1 , 4}$ & $\mathbf{1 , 2}$ & $\mathbf{1 , 4}$ \\
\multicolumn{2}{l}{ Özkaynak Çarpanı (Toplam Aktifler / Özkaynaklar) (X) } & & & & \\
Mevduat Bankaları & $\mathbf{2 0 1 5}$ & $\mathbf{2 0 1 6}$ & $\mathbf{2 0 1 7}$ & $\mathbf{2 0 1 8}$ & $\mathbf{2 0 1 9}$ & Ortalama \\
Kamu Sermayeli & 10,0 & 10,2 & 10,6 & 10,9 & 11,3 & 10,6 \\
Özel Sermayeli & 9,1 & 9,1 & 8,8 & 8,5 & 8,2 & 8,7 \\
Yabancı Sermayeli & 9,1 & 8,9 & 8,7 & 8,6 & 8,2 & 8,7 \\
Sektör Ortalaması & $\mathbf{8 , 9}$ & $\mathbf{9 , 0}$ & $\mathbf{9 , 0}$ & $\mathbf{9 , 0}$ & $\mathbf{8 , 9}$ & $\mathbf{9 , 0}$ \\
\hline Kaynak: Tulrkiye Bankalar & Birliğ
\end{tabular}

Kaynak: Türkiye Bankalar Birliği, 2020.

Tablo 3'e göre mevduat bankalarının 2015 - 2019 dönemi özkaynak karlılığ ile \%10,8 olan sektör ortalamasının altında kalmıştır. Ortalama aktif karlılığı ile özkaynak çarpanından oluşan özkaynak karlılığı bileşimine bakılarak bunun nedeni incelendiğinde; özkaynak çarpanının sektör ortalamasının üzerinde olmasına rağmen ortalama aktif karlılığın sektör ortalamasının altında olduğu görülmektedir. 2015 yılında özel sermayeli bankaların sektör ortalamasının altında özkaynak karlılığına sahip olmasının nedeni aktif karlılığının sektör ortalamasından düşük olmasıdır. 2016 yılında yabancı sermayeli bankaların \%12,3 olan özkaynak karlılığı $\% 13,5$ olan sektör ortalamasının altında kalmıştır. Bunun nedeni aktif karlılığ 1 ve özkaynak çarpanından oluşan özkaynak karlılığı bileşenlerinin her ikisinin de sektör ortalamasının altında kalmasıdır. 2017 yılında ise hem özel sermayeli hem de yabancı sermayeli bankalar sirasiyla $\% 13,6$ ve \%13,7 ile sektör ortalaması olan \%14,3'ün altında kalmıştır. Her iki banka grubunun da başarısızlığının temel nedeni aktif karlılığının ve özellikle de özkaynak çarpanının sektör ortalamasının altında kalmış olmasıdır. 2018 yılında özel sermayeli bankalar \%13,2 özkaynak karlılık oranı ile \%13,4 olan sektör ortalamasının altında kalmıştır. Özel sermayeli bankaların bu başarısızlığının nedeni aktif karlılığının sektör ortalamasının üzerinde olmasına rağmen 8,5 kat özkaynak çarpanı ile 9,0 kat olan sektör ortalamasının altında kalmasıdır. Aynı yılda kamu sermayeli bankalarının, \%1,2 aktif karlılığı ile \%1,4 olan sektör ortalamasının altında kalmasına rağmen, yüksek özkaynak çarpanı nedeni ile sektör ortalamasının üzerinde özkaynak karlılığına sahip olduğu görülmektedir. 2019 yılı özkaynak karlılığında hem kamu sermayeli bankalar hem de özel sermayeli bankalar sektör ortalamasının altında kalırken yabancı 
sermayeli banklar yaklaşık iki puan sektör ortalamasının üzerinde orana sahip olmuştur. Bu yılda kamu sermayeli bankalar \%8,7 ile sektör ortalamasının 2 puan altında kalarak en düşük özkaynak karlılığına sahip banka grubu olmuştur. Özkaynak karlılığı bileşenleri incelendiğinde bunun nedeninin kamu sermayeli bankaların 11,3 kat ile sektör ortalaması olan 8,9 katın üzerinde özkaynak çarpanına sahip olmasına rağmen, \%0,7 aktif karlılığı ile \%1,2 olan sektör ortalamasının 0,5 puan altında kalması olduğu görülmektedir. Bu durumda kamu sermayeli bankalar, yüksek özkaynak çarpanı ile özkaynaklara göre yüksek aktif bulundurmasına ve daha fazla risk almasına rağmen aktiflerin karlılığının düşük olması nedeniyle düşük özkaynak karlılığına sahip olmuşlardır.

Aynı çerçevede banka gruplarının 2015-2019 dönemi ortalama değerleri karşılaştırıldığında; \%11,9 ile sadece özel sermayeli bankaların sektör ortalaması olan \%12,5'in altında kaldığ1 görülmektedir. Bunun nedeni hem aktif karlılığının hem de özkaynak çarpanının sektör ortalamasının altında olmasıdır.

Tablo 3’e göre banka gruplarının 2015 - 2019 dönemi toplam aktiflerin özkaynaklara oranı olarak formüle edilen ve bankaların risk durumunu gösteren özkaynak çarpanı incelendiğinde; kamu sermayeli bankaların dönem boyunca en yüksek katsayıya sahip olduğu görülmektedir. Bu durum, kamu sermayeli bankaların daha fazla yabancı kaynak toplayarak fon kullandırdığını ve daha fazla risk aldığını göstermektedir. Bununla birlikte, 2015 yılında hem özel sermayeli bankalar hem de yabancı sermayeli bankalar, 2016 yılında özel sermayeli bankalar sektör ortalamasının üzerinde özkaynak çarpanına sahip olurken diğer yıllarda sektör ortalamasının altında kalmışlardır. Bu durum özel sermayeli ve yabancı sermayeli bankaların daha az risk üstlendiğini göstermektedir. Daha düşük özkaynak çarpanı aktif karlılığa bağlı olarak özkaynak karlılığını etkilemektedir.

\section{Aktif Karlılığı ve Bileşenlerinin Analizi}

Bankaların aktif karlılığı net karın toplam aktiflere bölünmesi ile elde edilmektedir. Ayrıca aktif karlılığına kar marjı ile aktiflerin verimliliğinin çarpılması sonucunda da ulaşılmaktadır. Kar marjı net karın toplam aktiflere bölünmesiyle, aktif verimliliği ise toplam gelirlerin toplam aktifle- 
re bölünmesi ile elde edilmektedir. Aktif karlılığı incelenen bankanın bu oranı diğer bankaların ortalamasını gösteren sektör ortalamasının altında ise bankanın performansının zayıf olduğu değerlendirilmektedir. Aktif karlılığı sektör ortalamasının altında olan bir bankada problemin kaynağını tespit etmek için bu oranı oluşturan bileşenlere bakmak gerekir. Problem ya kar marjının veya aktif verimliliğinin düşük olmasından kaynaklanır. Kar marjı düşük olan banka yeterli düzeyde finansal ürün ve hizmet satışı gerçekleştirmiş ancak düşük net kar elde etmiş demektir. $\mathrm{Bu}$ durum, banka çalışanlarının çabasının yeterli düzeyde kara çevrilememiş olduğunu göstermektedir. Aktif verimliliğinin düşük olması toplam aktiflerin yeterince gelir getirecek plasmanlarda değerlendirilmediğini göstermektedir. Banka aktiflerinden nakit değerler ve maddi duran varlıklar bankaların faaliyetlerinin sürdürülmesi için gerekli olan aktiflerden olsa da gelir getirici aktiflerden değildir. Tablo 4'te banka gruplarının 2015-2019 dönemi aktif karlılı̆̆1 ve bileşenleri incelenmekte, ardından tablo değerlendirilmektedir.

Tablo 4. Aktif Karlılı̆̆ı ve Bileşenleri

\begin{tabular}{|c|c|c|c|c|c|c|}
\hline \multicolumn{7}{|c|}{ Aktif Karlılığı (Net Dönem Karı / Aktifler) (\%) } \\
\hline Mevduat Bankaları & 2015 & 2016 & 2017 & 2018 & 2019 & Ortalama \\
\hline Kamu Sermayeli & 1,5 & 1,6 & 1,7 & 1,2 & 0,7 & 1,3 \\
\hline Özel Sermayeli & 1,0 & 1,5 & 1,5 & 1,5 & 1,2 & 1,3 \\
\hline Yabanc1 Sermayeli & $0,9^{*}$ & 1,4 & 1,5 & 1,6 & 1,5 & 1,4 \\
\hline$\underline{\text { Sektör Ortalamast }}$ & 1,2 & 1,5 & 1,6 & 1,4 & 1,2 & 1,4 \\
\hline \multicolumn{7}{|c|}{ Kar Marj1 (Net Kar / Toplam Gelir**) (\%) } \\
\hline Mevduat Bankaları & 2015 & 2016 & 2017 & 2018 & 2019 & Ortalama \\
\hline Kamu Sermayeli & 16,8 & 17,2 & 17,3 & 11,1 & 6,7 & 13,8 \\
\hline Özel Sermayeli & 13,0 & 16,0 & 16,7 & 13,1 & 10,5 & 13,9 \\
\hline Yabanc1 Sermayeli & 10,3 & 14,3 & 16,9 & 13,3 & 11,9 & 13,3 \\
\hline Sektör Ortalamast & 14,0 & 16,4 & 17,5 & 13,0 & 10,4 & 14,3 \\
\hline \multicolumn{7}{|c|}{ Aktif Verimliliği (Toplam Gelir/Toplam Aktifler) (\%) } \\
\hline Mevduat Bankaları & 2015 & 2016 & 2017 & 2018 & 2019 & Ortalama \\
\hline Kamu Sermayeli & 8,3 & 8,6 & 8,8 & 10,6 & 10,5 & 9,4 \\
\hline Özel Sermayeli & 8,3 & 8,7 & 8,8 & 11,4 & 11,0 & 9,6 \\
\hline Yabanc1 Sermayeli & 8,6 & 9,0 & 9,3 & 12,0 & 12,1 & 10,2 \\
\hline Sektör Ortalamast & 8,2 & 8,6 & 8,7 & 10,9 & 10,7 & 9,4 \\
\hline
\end{tabular}

Kaynak: Türkiye Bankalar Birliği, 2020.

${ }^{*} B u$ oran TBB verilerinde $\% 1,2$ olarak açılanmıştır. \%0,9 TBB verilerinde açıklanan net karın toplam aktiflere bölünmesi ile elde edilen sonuçtur.

${ }^{* *}$ Toplam Gelirler $=$ Faiz Gelirleri + Temettü Gelirleri + Net Ticari Kar/Zarar + Net Ücret Komisyon Gelirleri + Diğer Faaliyet Gelirleri

Tablo 4'e göre banka gruplarının 2015-2019 dönemi aktif karlılığ incelendiğinde; 2015 yılında kamu sermayeli bankalar \%1,5 ile \%1,2 olan 
sektör ortalamasının üzerinde orana sahip olurken, özel sermayeli bankalar \%1,0 ile yabancı sermayeli bankalar ise \%0,9 ile sektör ortalamasının altında kalmıştır. Hem özel sermayeli bankaların hem de yabancı sermayeli bankaların aktif karlığının sektör ortalamasının altında kalmasının nedenini belirlemek için aktif karlılığını oluşturan kar marjı ve aktif verimliliği değerlerine bakmak gerekir. Bu çerçevede özel sermayeli bankaların aktif verimliliği $\% 8,3$ ile $\% 8,2$ olan sektör ortalamasının üzerinde olmasına rağmen $\% 13,0$ olan kar marjı $\% 14,0$ olan sektör ortalamasının altında kalmıştır. Yabancı sermayeli bankalar da \%8,6 aktif verimliliği ile sektör ortalamasının üzerinde bir orana sahipken, \%10,3 kar marj1 oranına sahip olması nedeni ile aktif karlılığı sektör ortalamasının altında kalmıştır. Buna göre 2015 yılında hem özel sermayeli bankaların hem de yabancı sermayeli bankaların aktif karlılığının sektör ortalamasının altında kalmasının nedeni düşük kar marjı olduğu sonucuna ulaşılmaktadır. 2016 yılında kamu sermayeli bankalar \%1,6 ile \%1,5 olan sektör ortalamasının üzerinde, özel sermayeli bankalar $\% 1,5$ ile sektör ortalaması ile aynı iken yabancı sermayeli bankalar \%1,4 ile sektör ortalamasının altında kalmıştır. Yabancı sermayeli bankaların aktif karlılığı bileşenleri incelendiğinde; sektör ortalamasının altında kalmasının nedeni kar marjinın \%14,3 ile \%16,4 olan sektör ortalamasının altında olması sonucuna ulaşılmaktadır. 2017 yılında hem özel sermayeli bankalar hem de yabancı sermayeli bankalar \%1,5 aktif karlılı̆g 1 oranı ile $\% 1,6$ olan sektör ortalamasının altında kalmıştır. Bu olumsuzluğun nedenini bulmak için banka gruplarının aktif karlığı bileşenleri incelendiğinde; her iki banka grubunun da aktif verimliliği sektör ortalamasının üzerinde olmasına rağmen kar marjının sektör ortalamasının altında kaldığg görülmektedir. 2017 yılında özel sermayeli ve yabancı sermayeli banka gruplarının aktif karlılığının sektör ortalamasının altında kalmasının nedeni kar marjının sektör ortalamasından düşük olmasıdır. 2018 yılında sadece kamu sermayeli bankalar grubunun aktif karlılığı oranı sektör ortalamasının altında kalmıştır. Bunun nedenini belirlemek için aktif karlılığ incelendiğinde; hem kar marjı hem de aktif verimliliği sektör ortalamasının altında kaldığı görülmektedir. 2019 yılında kamu sermayeli bankaların \%0,7 aktif karlılık oranı ile \%1,2 olan sektör ortalamasının 0,5 puan altında kaldığ1 görülmektedir. Bunun nedeni incelendiğinde hem kar marjının hem de aktif verimliliğinin sektör ortalamasının altında kaldığı 
görülmektedir. Özellikle \%6,7 olan kar marjının \%10,4 olan sektör ortalamasının yaklaşık 3,7 puan altında kalması bu olumsuzluğun temel nedeni olmaktadir.

Aynı çerçevede Tablo 4'e göre banka gruplarının 2015-2019 dönemi ortalama değerleri karşılaştırıldığında; yabancı sermayeli bankalar \%1,4 ile sektör ortalaması ile aynı ortalama orana sahipken hem kamu sermayeli bankalar hem de özel sermayeli bankalar sektör ortalamasının altında ortalama orana sahip olmuşlardır. Banka gruplarının aktif karlılığ bileşenleri incelendiğinde üç banka grubunun da sektör ortalamasının altında oranlara sahip olduğu görülmektedir. Bu durumun temel nedeni sektör ortalamasında kalkınma ve yatırım bankalarının oranlarının da yer almasıdır. Dolayısıyla sektör ortalamasını yükselten oranların kalkınma ve yatırım bankalarına ait olduğu ortaya çıkmaktadır. Kar marjı oranı ortalamasında üç banka grubunun da sektör ortalamasının altında kalmasına rağmen, yabancı bankaların sektör ortalaması ile aynı aktif karlılığa sahip olmasının nedeni; sahip oldukları \%10,2 aktif verimliliği oranı ile sektör ortalaması olan \%9,4'un üzerinde olmalarıdır. Bu durum, yabancı sermayeli bankaların kamu sermayeli ve özel sermayeli bankalara göre aktiflerini daha fazla gelir getirici yatırımlarda kullandığını göstermektedir.

\section{Sonuç}

Çalışmada, DuPont çoklu oran analizi yöntemiyle Türk Bankacılık Sektöründe faaliyet gösteren mevduat bankaları kamu sermayeli, özel sermayeli ve yabancı sermayeli bankalar olarak sahiplik yapılarına göre gruplandırılarak finansal performans göstergesi olarak kullanılan özkaynak karlılığı ve bileşenleri karşılaştırmalı olarak incelenmiştir. Çalışma sonucuna göre, özkaynak karlılığı açısından 2015 yılında sadece özel sermayeli bankalar sektör ortalamasının altında kalmıştır. Ortalama aktif karlılığ 1 ile özkaynak çarpanından oluşan özkaynak karlılığı bileşimine bakılarak bunun nedeni incelendiğinde; özkaynak çarpanının sektör ortalamasının üzerinde olmasına rağmen ortalama aktif karlılığın sektör ortalamasının altında olduğu görülmüştür 2015 yılında özel sermayeli bankaların sektör ortalamasının altında özkaynak karlılığına sahip olma- 
sının nedeni aktif karlılığının sektör ortalamasından düşük olmasıdır. 2016 yılında yabancı sermayeli bankaların özkaynak karlılığı sektör ortalamasının altında kalmıştır. Bunu nedeni hem aktif karlılığının ve hem de özkaynak çarpanının sektör ortalamasının altında kalmasıdır. 2017 yılında hem özel sermayeli hem de yabancı sermayeli bankalar sektör ortalamasının altında kalmıştır. Her iki banka grubunun da olumsuzluğun temel nedeni aktif karlılığının ve özellikle de özkaynak çarpanının sektör ortalamasının altında olmasıdır. 2018 yılında özel sermayeli bankalar sektör ortalamasının altında kalmıştır. Özel sermayeli bankaların bu olumsuzluğun nedeni aktif karlılığının sektör ortalamasının üzerinde olmasına rağmen özkaynak çarpanının sektör ortalamasının altında kalmasıdır. Aynı yılda kamu sermayeli bankaların \%1,2 aktif karlılığı ile \%1,4 olan sektör ortalamasının altında kalmasına rağmen yüksek özkaynak çarpanı nedeni ile sektör ortalamasının üzerinde özkaynak karlılığ1na sahip olduğu görülmektedir. 2019 yılı özkaynak karlılığında hem kamu sermayeli bankalar hem de özel sermayeli bankalar sektör ortalamasının altında kalırken yabancı sermayeli bankalar yaklaşık iki puan sektör ortalamasının üzerinde orana sahip olmuştur. Özkaynak karlılığ 1 bileşenleri incelendiğinde; bunun nedeninin kamu sermayeli bankaların sektör ortalamasının üzerinde özkaynak çarpanına sahip olmasına rağmen, \%0,7 aktif karlılığ 1 ile \%1,2 olan sektör ortalamasının 0,5 puan altında kalması olduğu görülmektedir. Bu durumda kamu sermayeli bankalar, yüksek özkaynak çarpanı ile özkaynaklara göre yüksek aktif bulundurmasına ve daha fazla risk almasına rağmen aktiflerin karlılığının düşük olması nedeniyle düşük özkaynak karlılığına sahip olmuşlardır. Aynı çerçevede banka gruplarının 2015-2019 dönemi ortalama değerleri karşılaştırıldığında; \%11,9 ile sadece özel sermayeli bankaların sektör ortalaması olan \%12,5'in altında kaldığ1 görülmektedir. Bunun nedeni hem aktif karlılığının hem de özkaynak çarpanının sektör ortalamasının altında olmasıdır. 


\title{
EXTENDED ABSTRACT
}

\section{Analysis of the Financial Performance of Deposit Banks in the Turkish Banking Sector According to DuPont System: 2015-2019 Period}

\author{
Erdal Arslan- Ali Bora \\ Selcuk University
}

In the Turkish Banking System, deposit banks are grouped according to their capital structures as state-owned, private-owned and foreignowned banks. In this study, deposit banks operating in the Turkish banking sector are grouped according to capital ownership and their financial performance between 2015-2019 is examined comparatively according to the DuPont model. The DuPont system, also referred to as combined ratio analysis, was named with this name because it was first used by Du-pont, a chemical company, in 1919. This analysis method was first used by companies, then the model was developed and started to be used for the measurement of financial performance in the banking sector. In this system, the source of return on equity is analyzed in detail. The DuPont system is a multiple financial ratio analysis method that ultimately measures the outcome of the periodic activity of the business with return on equity. Return on equity is calculated by dividing the net profit at the end of the period by total equity. Return on equity can also be calculated by multiplying the return on assets and the equity multiplier. Considering that return on assets is obtained by multiplying profit margin by asset efficiency, return on equity; the profit margin can be calculated by multiplying the asset productivity and the equity multiplier. If there is a problem in the return on equity of the bank, this formula is a guide to find the source of this problem. Accordingly, if a bank's return on equity is below the industry average, it can be easily determined whether it is due to profit margin, asset productivity or equity multiplier.

In the study conducted by Ajmera (2012), one of the international studies that make bank performance analysis using the Dupont model, the financial health of the Indian banking sector between 2006 and 2011 was 
analyzed with the DuPont model. In the study conducted by Balaj (2015), the financial performances of domestic and foreign banks in Kosovo for the 2001-2007 period were analyzed comparatively using the DuPont financial analysis model. In the study conducted by Haider (2016), the financial profitability of Baroda Bank and HDFC Bank, one of the largest public and private banks in the Indian banking sector, was analyzed using the Dupont method. In the study conducted by Rooplata (2016), the performance of 19 national banks in India was analyzed using DuPont analysis method. In the study conducted by Rahman and Mia (2018), the financial performances of 15 Bangladesh commercial banks for the period 2010-2016 with DuPont method were examined. In the study conducted by AlAli (2019), the financial performances of Kuwait banks for the period of 2012-2017 were analyzed according to the DuPont system.

In addition to studies on countries, there are also studies on the financial performance of banks operating in the Turkish Banking Sector. Among them, Önal and Sevimeser (2006) compared the activities of banks operating in the Turkish banking sector according to their ownership structures. In the study of Aktaş and Kargın (2007), foreign banks operating in the Turkish banking system between 2003 and 2006 were compared with national (public and private) banks in terms of some financial ratios. Akbulut and Albayrak (2009) studies, the performance of banks in terms of the ownership structure in Turkey and examined it decomposes according to which the ownership structure of these factors. In the study conducted by Yucel (2009), the 3 public operating in Turkey, 10 private owned banks, and 11 of them were established in Turkey consisting of foreign banks, 24 banks were assessed performance between 2002-2007. In the study conducted by Demirel, Atakişi andAbacioğlu (2013), the activity rates and profitability indicators of private, public and foreign deposit banks were analyzed using quarterly data between March 2002 and June 2012. In the study conducted by Gümüş and Nalbantoğlu (2015), the performance of the Turkish Banking Sector, which consists of public, domestic private, foreign capital and participation banks, in the period of 2002-2013, was analyzed comparatively with the CAMELS analysis method. In the study conducted by Gümüş and Çıbık (2018), equity efficiency analyzes of 25 companies among real esta- 
te investment trust companies traded in the stock exchange were made using the DuPont method.

State-owned deposit banks between the years 2015-2018, while getting a return on equity above the industry average achieved a return on equity lower than the sector average in 2019, private-owned deposit banks under the industry average, foreign-owned deposit banks particularly in 2018 and 2019 have return on equity above the industry average. When the results of the study are analyzed in detail, only private banks remained below the sector average in 2015 in terms of return on equity. When the reason for this is examined by looking at the composition of return on equity consisting of average return on assets and equity multiplier; although the equity multiplier is above the sector average, it is seen that the average return on assets is below the industry average. The reason that private banks have a return on equity below the sector average in 2015 is that their return on assets is lower than the sector average. In 2016, the return on equity of foreign banks remained below the sector average. The reason for this is that both the return on assets and the equity multiplier are below the industry average. In 2017, both private and foreign banks remained below the sector average. The main reason for the negativity of both bank groups is that the return on assets and especially the equity multiplier is below the sector average. Private banks remained below the sector average in 2018 . The reason for this negativity of private banks is that although their return on assets is above the sector average, the equity multiplier is below the sector average. While both state-owned banks and private banks remained below the sector average in return on equity in 2019, foreign banks had a ratio of approximately two points above the sector average.

\section{Kaynakça / References}

Ajmera, B. C. (2012). Analysis of financial health of banking industry through Dupont model. Global Journal of Research In Management (GJRIM), 2(2), 5875 .

Akbulut, R. ve Albayrak, A. S. (2009). Mevduat bankalarında performansın mülkiyet yapısına göre finansal göstergelerle incelenmesi. Finans Politik \& Ekonomik Yorumlar, 46(530), 27-40. 
Aktaş, H. ve Kargın M. (2007). Türk bankacılık sektöründeki yabancı ve ulusal bankaların finansal oranlar açısından karşılaştırılması. Yönetim ve Ekonomi, $14(2), 31-45$.

Alali, M. S. (2019). The use of Dupont modified financial model in evaluating the financial performance of Kuwaiti banks. Journal of Banking and Financial Dynamics, 3(1), 1-9.

Arslan, E. (2017). Türk bankacllı sisteminde aktif büyüklüğüne göre ilk yedi bankanın karlılık ve verimlilik açısından karşılaştırmalı analizi: 2003 - 2015 dönemi. Sosyal Ekonomik Araştırmalar Dergisi, 17(34), 226-247.

Ata, H. A. (2009). Banka yabancılaşmasının Türkiye'deki yerli ve yabanc bankalar açısından karşılaştırılması. Atatürk Üniversitesi İktisadi ve İdari Bilimler Dergisi, 23(4), $109-124$.

Balaj, D. (2015). A Comparison of financial performance of domestic and foreign banks in Kosovo by using Dupont model. Acta Universitatis Danubius. OEconomica, 11(6), 71-86.

Berk, N. (2000). Finansal yönetim (5. Bb.). İstanbul: Türkmen Kitabevi.

Demirel, E., Atakişi A. ve Abacıoğlu S. (2013). Bankacılık faaliyet oranlarının panel veri analizi: Türkiye'deki kamu, özel ve yabanc sermayeli bankaların durumu. Muhasebe ve Finansman Dergisi, 59, 101 - 112.

Gümüş, U. T. ve Çıbık, E. (2018). Borsa' da işlem gören gayrimenkul yatırım ortaklığı işletmelerinin birleşik oran analizi (Dupont) yöntemiyle performansının ölçülmesi. Hitit Üniversitesi Sosyal Bilimler Enstitüsü Dergisi, 11(3), 2178-2194. doi:10.17218/hititsosbil.421602.

Gümüş, F. B. ve Nalbantoğlu, Ö. (2015). Türk bankacllı sektörünün CAMELS analizi yöntemiyle 2002-2013 yılları arasında performans analizi. Afyon Kocatepe Üniversitesi İktisadi ve İdari Bilimler Fakültesi Dergisi, 17(2), 83 - 106.

Haider, A. (2016). Comparative analysis of financial efficiency of bank of Baroda and HDFC bank using Dupont model. International Journal of Research in Management, Economics and Commerce, 6(8), 9-18.

Kandemir, T. ve Arıc, N. D. (2013). Mevduat bankalarında Camels performans değerleme modeli üzerine karşılaştırmalı bir çalışma (2001-2010). Süleyman Demirel Üniversitesi İktisadi ve İdari Bilimler Fakültesi Dergisi, 18(1), 61 - 87.

Önal, Y. B. ve Sevimeser, N. C. (2006). Yabancı banka girişlerinin Türk bankacılık sistemine etkileri: yerli ve yabanc bankaların etkinlik analizi. Ç.Ü. Sosyal Bilimler Enstitüsü Dergisi, 15(2), 295-312. 
Rahman Z. and Rubel M. (2018). Deconstruction of ROE: An implementation of DuPont model on selected Bangladeshi commercial banks. International Journal of Economics and Financial Research, 4(6), 165-170.

Rooplata P. (2016). DuPont analysis of nationalised banks in India. International Journal of Management, IT \& Engineering, 6(12), 211-223.

Rose, P. S. and Fraser D. R. (1988). Financial institutions: Understanding and managing financial. Texas: Business Publications.

Tandon, D.; Singh, H. and Singh K. (2016). Profitability valuation in Indian banks emperics via David Cole model. IOSR Journal of Business and Management, 2(special issue), 64-83.

Türkiye Bankalar Birliği (2020). Türkiye'de bankacıllk sistemi 1959 - 2019. Temmuz. Erişim adresi: https://wwww.tbb.org.tr/tr/bankacilik/banka-ve-sektorbilgilerilistatistiki-raporlar/59 (22.09.2020).

Yücel, L. İ. (2009). Türkiye'de faaliyet gösteren kamu bankaları, özel sermayeli bankalar ve yabancı bankaların performanslarınin 2002-2007 döneminde temel bileşenler ve faktör analizi ile değerlendirilmesine ilişkin bir uygulama. Yönetim ve Ekonomi Araştırmalan Dergisi, 7(12), 118 -138.

\section{Kaynakça Bilgisi / Citation Information}

Arslan, E. ve Bora, A. (2021). Türk bankacıllk sektöründe mevduat bankalarının finansal performanslarının DuPont Sistemine göre incelenmesi: 2015-2019 dönemi. OPUS-Uluslararası Toplum Araştırmaları Dergisi, 18(43), 6356-6376. DOI: 10.26466/opus.930091. 